\title{
The Influence of the Difference between Chinese and Western Culture on Advertising Translation and Strategy
}

\author{
Xin Zheng \\ School of Foreign Languages, Shanxi Normal University, Linfen 041000, China
}

\begin{abstract}
Since China became a member of the WTO in 2001, more and more Chinese products have an opportunity to enter the international market, and begin to compete with foreign brands. Advertising as a means of mass media, it happens able to introduce the foreign goods to domestic consumers, and to promote the Chinese products to foreign consumers. In such a social background, the importance of advertising translation has become increasingly prominent. The paper tries to analyze the characteristics of advertising language and the influence of the difference between Chinese and western culture on advertising translation by organizing the successful and unsuccessful English and Chinese advertising translation corpus collected over the several years. It pointed out that the advertising translation not only achieves the purpose of language conversion, but also takes into account the influence of language and cultural differences. Finally, through the analysis of advertising language, exploring some effective translation methods and strategies, such as: literal translation, free translation, amplification, corresponding translation and creative translation, which can put forward reference and guidance on advertising translation so that the author can achieve the properly translation of advertising. Hope to assist advertising translators.
\end{abstract}

Index Terms - cultural differences, language features, advertising translation, translation strategies

\section{INTRODUCTION}

Advertising exists for long time. People of modern society have already been very familiar with advertising, which can be seen or heard anytime and anywhere. Nowadays, advertising has become an industry itself.

With the rapid development of science and technology, the economic cooperation between countries is gradually expanding. In the face of opportunities and challenges, many countries are expected to increase their economic strength in the foreign trade, and advertising provides the international market by selling goods and an important means of competition. Therefore, the author should do a good job in translation in international trade, and the importance is self-evident.

There is no doubt that cultural differences between China and Western countries have a profound impact on advertising translation, so the author must take into account the cultural factors when exploring the translation methods of advertising. Then, studying the translation of successful and unsuccessful English and Chinese advertising translation corpus, drawing lessons from the previous summary of the translation methods, for example: literal translation, free translation, amplification, corresponding translation and so on to find the most suitable translation method of advertising, we aim to further deepen the understanding of the characteristics and influential factors of advertising, so that the conclusion of research could be applied to the translation practice.

In this thesis, the author makes efforts to analyze the features, influences by using some typical examples, and puts forward several practical strategies and skills for the advertising translation.

\section{LingUistic FEATURES IN ADVERTISEMENTS}

As a kind of applied languages, advertising has many differences such as word, sentence and rhetoric. In order to attract readers on advertisement, lots of advertisements are the fruits of deep consideration, with their beautiful words, simply in structure but rich in meaning as well as variable in figure of speech (Wang, 2010). Good advertising not only has the function of communication and persuasion, but also brings the highly commercial value.

\section{A. Lexical Features}

1. Use of Simple Words

Advertising language always uses some common colloquial words, which are simple and appealing, for example:

Enjoy Cola. 享受可口可乐. (可口可乐)

Ideas for Life. 为生活着想. (松下电子)

Impossible is nothing. 没有什么不可能的. (阿迪达斯) 
The primary characteristics of advertising language are simple and chic, and it can gift with an extraordinary retentive memory so long as readers get a glimpse of them. Simple words impress the audience and maximize the propaganda effect of advertisements.

\section{Repetition Use of Words}

Highlight a strong sense of emotion through the repetition of some key words and phrases, forming the strong rhythm on the rhyme, for example:

Double Delicious, Double Your Pleasure. 双份美味, 加倍愉快. (某食品广告)

Good Teeth, Good Health. 牙齿好，身体就好. (高露洁牙膏)

用了“蚊不叮”，蚊子就不叮. (“蚊不叮”驱蚊药)

In advertising, repetition use of words can highlight the publicized products which are different from other brands in aspects of features and functions to meet certain demands of consumers.

\section{Use of New Words}

Create new words or strange words in order to stand out the new, strange and special aspects of products and to meet the consumer's psychology of pursuing fashion and extolling personality, for example:

The orangemostest drink in the world.

This is a beverage advertisement in which "orangemostest" = "orange + most + est", and "most" and "est" which are used beside the "orange" represent the good quality, high concentration and pure taste of products. Many English prefixes, suffixes, such as "super", "ex" often appear in advertising language to emphasize the high quality of the product, such as "supernatural, superfine" and "Rolex, Kleenex".

\section{B. Syntactic Features}

\section{Use of Simple Sentences}

Features of spoken language are strong in simple sentences, and they are not only very close to author's life, moving people, but also play their advertising effects, making consumers understand and remember them, for example:

Your Home in the Air. 您在空中的家. (航空公司)

I can play. 我能, 无限可能. (匹克)

一嗑就开心. (阿里山瓜子)

运动快乐. (运动快乐)

Compared with the complex sentences, the simple sentences with more sonorous and forceful tone are easy to understand. Moreover, most vocabularies are basic and easy to remember, so the advertisements read very smoothly, which can achieve the effect of attracting foreign consumers.

\section{Use of Imperative Sentences}

With its unique style, great charisma and persuasive, imperative sentence favored by advertisers, they are frequently used in advertising. For example:

Keep moving. 永不止步. (安踏)

Just do it. 只管去做. (耐克运动鞋)

Take time to indulge. 尽情享受. (雀巢冰激凌)

The imperative sentence itself implied request, command or advice. The function of imperative is in line with the convictive purpose of these functions, so it can well serve for advertisements. Advertisers use imperative sentences in the advertisements in order to advise and encourage people to take actions to buy the advertised products.

\section{Use of Compound Sentences}

Compound sentences are more attractive and persuasive than simple sentences, such as:

We lead, others copy. 我们领先, 他人效仿. (理光复印机)

Tide’s in, Dirt's out. 汰渍到, 污渍逃. (汰渍洗衣粉)

透心凉, 心飞翔! (雪碧)

Although advertising language is exquisite and concise, it has to show the features, functions and ideas of products so as to convince consumers. Compound sentences are able to achieve both expression completely and language concisely.

\section{Use of Idioms}

Idiom is a kind of conventional language phenomenon, and its expression and meaning have been a deep-rooted thought in the public. Generally speaking, it is difficult to change. However, in particular language environment, innovation and flexibility in the use of slangs and idioms are able to bring about unexpected results, which have been fully utilized in advertisements, for example:

A Dove a day keeps you work, rest and play. 一天一块德芙巧克力,给你工作,休闲,娱乐添活力. (德芙巧克力)

This advertisement is derived from two other well-known idioms: An apple a day keeps the doctor away (一日一 苹果, 医生远离我) / All work and no play make Jack a dull boy(只干工作不玩要, 聪明小孩也变俊). The chocolate advertising of dove not only brings in idioms in language form, as well as uses the content of the two idioms indiscriminately. 


\section{Rhetorical Devices}

In order to improve expression ability of advertising language, strengthen its expressive effect, and arouse the interest and desire for consumers to buy goods, people pay much attention to the aesthetic perception of the advertising language, so that there is an extensive use of rhetorical devices ( $\mathrm{Wu}, 2012)$. The most common figures of speech are analogy, personification, pun, hyperbole, etc.

\section{Analogy}

The application of metaphor rhetoric makes consumers have a more detailed understanding of products. At the same time, it achieves the goal of promotion. The two skills which are used commonly include simile and metaphor.

Simile is the directly use of figurative words (such as like, as, as if and so on), then the products can be directly compared to something in author's life, for example:

Fly smooth as silk. 丝般润滑. (泰国航空公司)

母亲的手一样舒适. (某牌婴儿鞋)

According to the common characteristics or intrinsic links between the two things, putting the name of one thing to another thing, the speaker does not directly name but rely on his/her own understanding called metaphor.

You'd better off under the umbrella. 你最好在保护伞下. (旅游保险)

This is a travel insurance company's advertising. As for travel, travelers are most concerned about the safety. Using common psychology of tourists, and travel insurance company uses umbrella as the metaphorical object, making the passengers feel-vivid to buy insurance, go out for travelling, just like being under an umbrella, the tourists can enjoy the journey. "Better off" has the meaning of "comfortable and happiness", that is to say, the purchase of such insurance can make the author's travel more comfortable and enjoyable. Advertising is very short, but metaphorical. Object is vivid, allowing visitors to feel more cordial and authentic for the service of insurance company.

\section{Personification}

Personification is also one of the rhetoric methods used in advertising. It is used for publicizing things in order to make it personal and emotional. For example:

天天想爱你一伴你一日三餐, 伴你年年月月. (“家乐”调味品系列广告)

Apple think different. 苹果电脑, 不同凡 “想”. (苹果笔记本)

Jobs, the CEO of Apple, returned to the company in 1997 and launched the famous advertising" Apple think different ", giving Apple the idea of passing on the value of Apple. So, what kind of people does apple stand for? Those are people who have independent thought; who have the courage to abandon a narrow vision; who are willing to try new things; who are not likely to be mediocre and unambitious in order to pursue personal ideal by unremitting efforts and who want to change the world. The value of "Think Different" determines the target user group of Apple Cooperation. The Apple will focus on those users and meet their ultimate experience. Therefore, the Apple sets off a wave of panic buying boom in China.

The world smiles with Reader's Digest.

《读者文摘》, 欢乐开怀. (《读者文摘》)

The advertisement not only brings joy to readers, but also stresses its influence throughout the world, achieving many things at one stroke and attracting readers.

\section{Pun}

The pun is a kind of rhetorical devices. Words in it are concise, humorous and novel which can highlight the features of products, so there are a large number of applications in the advertisement.

按耐不住, 就快滚. (微软鼠标)

要想皮肤好, 早晚用大宝. (大宝)

This is a slogan of Dabao cosmetic products company. The first layer of meaning is said that consumers can maintain the skin if they use Dabao cosmetics in the morning and evening. This is the first reaction for most people who have thought after reading. But there is a deeper meaning, that is, no matter how many cosmetic products used before, the consumers have to rely on Dabao cosmetics. This is the profound meaning of this advertisement. Readers can find the deeper meaning and get the pleasure after thinking while reading the advertisement, which can deepen the impression of the brand.

Ask for More. 再来一支, 还吸摩尔. (“摩尔”牌香烟)

"More" (摩尔牌) is one of America's cigarette brands, which is popular among female smokers for its slender body and soft smoke. "More" and "more" have the same pronunciation, but different in meanings, and consumers will naturally connect the meaning of MORE cigarette with the meaning of "more". The use of pun in the advertisement has a dual role in selling goods.

\section{Hyperbole}

Hyperbole refers to deliberately exaggerate or shrink the image of things so as to highlight certain features or characters of things, and express emotions vividly. For example:

Intelligence Everywhere. 智慧演绎, 无处不在. (摩托罗拉手机)

We've hidden a garden of vegetables where you'd never expect. In the pie. 在您想不到的地方, 我们珍藏了满 


\section{园的蔬菜. 就在一个小小的馅饼中. (馅饼)}

特步, 飞一般的感觉. (特步牌运动鞋)

This is the advertising of XTEP sports brand, which is a typical example of hyperbole. Obviously, no matter what the brand of sports equipment is, there would never have a general feeling of flying. However, after watching this advertisement “特步,飞一般的感觉”, the author has a sense of novel. The appropriate degree of exaggeration not only does not damage the brand image, but also makes consumers have a new understanding of the brand.

\section{The Cultural DifFERENCES IN AdVERTiSing TRANSLATION}

Because of the different social culture, the perspective of Chinese and English is also different when observing or treating things, there may be contrary to the original version of the text in the translation of advertising. Translation is a cross-language and cross-cultural communicative activity. Eugene A Nida (1993), one of famous American translation theorists, pointed that: "Translation is an exchange between two cultures. For a real successful translation, understanding two cultures is more important than knowing two languages, because words become meaningful only in their effective cultural background" (p.248). Therefore, translators should not only consider the features of advertising, but also pay more attention to the cross-cultural factors.

\section{A. Cultural Value Differences}

Chinese have a profound humanism spirit, and they regard "introspection", "restraint" as criterions so that people are always introverted. In the treatment of things, people pay more attention to the content and demonstration; while the westerners are more outgoing, focusing on the external form and the effect of the senses. The different cultural values lead to different cultural characteristics. The Chinese are deeply influenced by traditional culture and have a strong sense of authority worship. However, the cases are different for westerners. They pay more attention to individuality and personality, taking "personality", "independent", and "privacy" as the theme.

默默奉献, 为香浓加分! (雀巢公司的广告)

The advertisement emphasizes the spirit of dedication. However, in the United States, its corresponding advertising is "coffee's perfect mate". (咖啡的完美伴侣!) "Mate" illustrates the relationship between coffee and coffee mate is equal. Mixing them together, and then people can enjoy the mellow and delicious coffee. If this Chinese advertisement is directly translated into English, I am afraid that it will not leave a good impression to American consumers. Because Americans believe in freedom and individualism and that everyone is equal, "Dedication" will make Americans lose themselves. Through this example, the author can clearly understand that different cultures determine different values.

In addition, some public services advertisements also reflect the differences between eastern and western cultural values. Let us see some of them as follows:

No alcohol allowed rather than Don 't drink alcohol. 严禁酗酒.

No parking rather than Don 't park. 不准停车.

No overtaking rather than Don 't overtake. 严禁超车.

The differences in the final examples are the focus of the power of the group and individual tendencies.

\section{B. Historical Culture Differences}

Different countries have different history, which is reflected in the translation of advertisements. The author should take into account the history and culture of different countries. Japan's Toyota car has done this. The advertisement of Toyota when entering into the Chinese market is "车到山前必有路,有路必有丰田车", which is derived from one of Chinese well-known idiom “车到山前必有路”, but it is difficult for Americans to understand. Therefore Toyota changed the slogan of American into "Not all cars are created equal", which applies the sentence in the Declaration of independence "all men are created equal" (人人生而平等), so it expresses that Toyota has better quality than other cars.

Another example is a travel company which makes full use of the competition between domestic political parties for their own publicity. "Butlin's - the right choice. Don't labour the point, or be conservative in your choice or liberal with your money. Come to Butlin's for the real party. Great Party Ahead." The "labour", "conservative" and "liberal" are all the name of the political parties, and "party" also has the meaning of political party. Obviously, it uses the pun rhetoric, but if the translator does not understand the political background of the country, and it is hard to experience the wonderful meaning these words covey.

As is known to all, China is the socialist system, while the most western countries are the capitalist system. To some extent, the differences of these two kinds of social institution affect people's life. Take certain public service advertisement as an example:

五讲四美三热爱.

Version one: Five stress, four beauties and tree lovers.

Version two: Five stress, four points of beauty and tree aspects of love.

From the version one, westerners are easy to misunderstand it as “四个美人和三个情人”, which makes the 
advertising lack its original commonweal and even runs in opposite direction. However, the version two seems more serious, in accordance with the cultural appeal under the socialist system.

\section{Thought Pattern Differences}

Chinese and English advertisements show the different thought patterns. Chinese traditional culture advocates conservative and implicit, and Chinese believe that the implicit language is very meaningful. Sometimes it can reach the desired state. Compared with the English version, direct expression of the advertising is more accord with western style. For instance:

To me, the past black and white, but the future is always color. (Hennessy)

对我而言, 过去平淡无奇; 而未来, 却是绪烂缤纷. (轩尼诗酒)

Good to the last drop. (Maxwell)

滴滴香浓, 意犹未尽. (麦斯威尔咖啡)

Start ahead. (Rejoice)

成功之路, 从头开始. (飘柔)

Thinking mode of Chinese is abstract. When people see an object, they will think of another thing associated with this object. Therefore, advertisers often use a specific scene equally or a metaphor so that consumers can easily think of related products, for example:

As if lying in the snow-white clouds. 犹如躺在洁白的云朵里. (鸭线被)

鹤舞白沙，我心飞翔. (白沙牌香烟)

\section{National Culture and Custom Differences}

Different nationalities have different beliefs and customs, and the differences will be reflected in their own language. The author should pay attention to avoiding using the language symbols which may send the wrong information. For example, the "dragon" has the meaning of "holy, noble and auspicious" in Chinese, which is viewed as a symbol of power and status; while in the eyes of the westerners, "dragon" is a symbol of "evil and cruel". Therefore, when the translators translate the advertisement with the "dragon", they should do some disposal properly. There is a tourism advertising in Chinese like this: “西峡一开放的龙乡.” The English version is "Xixia, home of Di-Nosaurs - open to the world." It is artful to change the "dragon" into "dinosaur", avoiding the sense of fear for western tourists because of the word "dragon" and catering to their adventurous psychology.

Another example is called "Goldlion", which is a brand of well-known international tie. It is said that the name of the tie was originally the "lucky lion", and "lion" is the same as "lost" in Cantonese pronunciation so that the business is bleak. Once it is translated into "Goldlion", the business is booming, because the target language meets the mentality of Chinese for seeking good luck and fortune.

\section{E. Aesthetic Value Differences}

The translation of advertisements can be influenced by the aesthetic value of differences between the source language and the target language. Chinese often write the article emphasizing on diction, ornate, and "language not astonishing oath endlessly". It is difficult for westerns to accept the exaggeration. Most of food, nourishing and beautifying classes of advertisings are blowing up. If the author translates them directly, it will cause resentment in western consumers and refuse to accept.

In China, people use a lot of words to describe that the skin of person is good, such as “白嫩, 白晳, 粉白, 白里 透红”, and people think that "a white covers three ugly". This kind of aesthetic characteristic of Chinese makes cream products at home all claim that theirs products have the effect of whitening. This view, however, is contrary to the international trend of aesthetic appreciation. As for westerners, "black" is regarded as a healthy color, "黑里透红 " is a symbol of health, while "white" represents poverty and disease. Therefore, the author must consider the aesthetic differences in the translation of cosmetics advertising.

\section{AdVERTiSing TRANSLATION STRATEGIES}

\section{A. Aim of Advertising Translation}

Advertising can achieve many purposes. The Association of National Advertisers classifies the advertising according to its purpose as follows: "Awareness, Comprehension, Conviction and Action (ACCA)" (Guo, 1963, p.73). People know the products and service by listening, reading advertisement, understanding the use and the scope of business and convincing themselves to buy the products or to enjoy the service. This is the purpose of advertising translation. Therefore, how can the author make this purpose come true? In other words, what are the advertising translation strategies?

\section{B. Approaches to Advertising Translation}

In China, "faithfulness, expressiveness and elegance", which are put forward by Yan Fu, are the general principles for translators. However, advertising translation is different from the other translations, which is a kind of economic 
activity. Specifically, advertising translation is for the readers, that is, for consumers, so the translation should take into account the consumer's psychology. Whether the advertisement is successful or unsuccessful, it depends on the consumer's response. The readers, that is, consumers occupy an important role in the process of advertising translation, which is the unique feature from other translations. Therefore, translators should take full consideration of the age, gender, social status and shopping psychology of consumers when they choose translation methods.

\section{Literal Translation}

Peter Newmark, one of the most famous translators of Britain, who said "The SL grammatical constructions are converted to their nearest TL equivalents but the lexical words are again translated singly, out of context. As a pre-translation process, this indicates the problems to be solved" (Newmark, 2001, p.153). Literal translation is loyal to the advertisement language. In the process of translation, the author often regards the word as the basic unit of advertisement translation, considers the constraints of context, keeps the meaning and structure of the original, reproduces the form, content and style, that is to say, gaining the similar advertising effectiveness as the original, and maintains the original beauty at the same time. As for some advertisements, the original meaning is explicit and the syntactic structure is simple. The author can achieve both the surface meaning and deep meaning by translating directly. Using of the literal translation, the information can be expressed clearly, and the surface meaning accords with the deep meaning (Zou, 2005). It mainly uses between the original and the target language for its cultural commonality, which can produce the same association among people. For example:

At 60 miles an hour the loudest noise is this new Rolls-Royce comes from the electric clock.

时速 60 英里的这种新式“劳斯莱斯”轿车最响的噪音是来自车内的电钟.

The advertisement of Rolls-Royce car is a masterpiece of the famous American advertising designer-David Ogilvy, and it is also the best example for people to demonstrate the effect of literal translation. Although the original is very simple, the conception is special. According to the principle of literal translation, the advertisement can both maintain the original style and have a good effect. Literal translation is a good way for translators, because it can keep the style of the original.

Challenge the Limits.

挑战极限. (SAMSUNG)

Similarly, the advertising only includes four characters, which is simple and concise. It not only implies the continuous pursuit for Samsung itself to break through the boundaries of science and technology, but also encourages people to break through themselves and the limit of life. It shortens the distance from consumers and reflects perfectly the spirit that Samsung company wants to convey.

All is well that ends well.

Version one:烟蒂好,烟就好.

Version two:越抽到后头越有味道.

The advertising comes from As You Like It written by William Shakespeare, who is one of the most greatest English writers. The implication is that the outcome is good and everything is good. The version one is really confusing. The quality of cigarettes lies in tobacco, ingredients, not in the cigarette holders. As for the “烟蒂”, it refers to the butt remained after having a smoke. How can we say that “烟蒂好,烟就好”? The author fears that the meaning of the advertising should be “越抽到后头越有味道”. The version one is too faithful and straightforward to the original. So when the author sees the "end", the author will immediately regard it as the butt. In fact, this is a word which has cultural meaning. This advertisement wants to use Shakespeare's masterpiece to arouse the psychological resonance among people. This is a natural association. For translators, whether the translation is successful or not, it depends on whether they are familiar with the common sense of British literature, and it is important that whether he can flexibly use their background knowledge and correctly interpret the cultural connotation rather than simply copy the content without consideration. The version one is just a copy of the meaning, and it does not consider what the advertising wants to promote. Cigarette or cigarette butts? So it focuses on the first half of the sentence. That is to say, the butts of their cigarettes are very good, so the cigarettes are certainly excellent. Of course, the logic is unreasonable. In contrast, version two puts the cultural factors into the goods. The "end" here does not refer to the butt, and it refers to the feeling when people are smoking.

Unlike me, my Rolex never needs a rest. (Rolex)

与我不同, 劳力士从不需要休息. (劳力士手表)

The advertisement takes the method of literal translation. It personalizes the products by using primitive rhetoric and makes the products full of human touch. The surface meaning describes that the Rolex watches run accurately and never needs to be repaired. The deep meaning conveys the connotation of the good quality and trustworthy of the products.

The above examples have maintained the linguistic forms and cultural characteristics of the source texts, which are the very faithful translations.

\section{Free Translation}

Newmark advocated that free translation reproduces the matter without the manner, or the content without the form of the original. Usually it is a paraphrase much longer than the original so-called 'intralingual translation', 
often prolix and pretentious, and not translation at all (Newmark, 2001, p.145). The free translation does not rigidly follow the form and structure of the original. That is to say, the free translation is an effective way to solve the problem if the statement which is directly translated does not conform to the common expression or literal translation ( $\mathrm{Li}, 2010)$. The author should pay more attention to the meaning of words in original, combining context to choose words in order to express the actual meaning of original accurately. Translators usually have some creativity, but the basic information of the original should be retained. There is a typical example:

A diamond is forever. (De Beers)

钻石恒久远，一颗永流传. (戴比尔斯钻石广告)

Compared to other literary forms, advertising pays more attention to social factors, such as economy and culture, and emphasizes the effectiveness and acceptability of language. In addition, it emphasize on the creative use of words. Easterners and westerners know that the diamond has a very high value, which represents the steadfast emotion. Love is romantic, and if people buy a diamond for lovers, it represents the love between them is firm and eternal. But the westerners prefer to direct expression, so the original advertising language is concise and very suitable for oral communication. However, if the author just translates the advertisement as "一颗钻石就是永远", it will lack the uniqueness of the original advertisement. The translation lacks the flavor of the original advertisement while reading. On the guidance of free translation, the author translates it as “钻石恒久远,一颗永流传”, and it will have a very different effect. It not only has the readability of the original advertisement, but also accords with the implicative expression of Orientals in order to persuade consumers to accept the advertised things and take action to buy.

Every Time a Good Time. (McDonald's)

秒秒钟欢聚欢笑. (麦当劳)

As for this advertisement, the author translates it under the principle of literal translation as "每一刻都是美好时 光". It is loyal to original on the semantics, and sentence pattern, but it seems a little mediocre. However, for a fast-food chain, "秒秒钟欢聚欢笑" just as a wonderful lens which is cut out from the film. Who can resist the temptation?

Focus on Life. (Olympus)

人生难忘片段, 永远印记. (奥林巴斯相机)

This is an advertising of camera, and it tightly focuses on the function of camera. That is to say, the camera keeps the unforgettable memories of people. It makes people feel that business is standing on the point of view of the customers rather than selling their goods. “永远印记” also implies that pictures made by camera of Olympus have a reliable quality and can be retained forever.

The above translations can't reproduce the original in the same language, but they are highly refined so that the deep meaning of the translations is equivalent to the original.

\section{Amplification}

As the translator Newmark mentioned: "for a professional translator, if the target language is more abundant than the source language in vocabulary, grammar and rhetoric, using the characteristics of the target language flexibly to translate can greatly improve the level of translation." Chinese are good at using parallelism, symmetry, idioms to convey ideas and information. In the process of advertisement translation, the author should take into account these factors and adopt appropriate translation strategies to increase the component which is not expressed by English but necessary for Chinese.

Beyond Your Imagination. (Korean Air)

意想不到的天空. (大韩航空)

This advertisement can be translated as "超乎你的想象" literally, and it is very faithful to the desirable translation. However, there are too many things beyond the author's imagination. Would people like to experience an unexpected sky? Come on Korean Air. Actually, the sky is same no matter which airline plane people are taking. However, under the guidance of amplification, it is difficult for passengers to resist the mystery brought by translation: take Korean Air and people can have a different sky.

Cut, Colour, Clarity and Carat Weight.

造型别致, 色彩斑斓, 晶莹剔透, 重量保证.

The advertisement is designed for the diamond. The original uses alliterative technique, but this effect is very difficult to be reflected on translation. Therefore, the translator has to abandon the original way of expression, translating the brief words of the original into the four four-letter words in Chinese which are concise, sonorous and forceful. Although the translation has changed the form of the original text and adds some content, its meaning is still very clear and the form is also beautiful.

Obviously, the translation can reveal more information by mining the deep meaning of the original, and it can make the customers know the products and then accept the brand culture.

\section{Corresponding Translation}

Because of the different cultural background, the image of the original is sometimes not in accordance with the Chinese customs. Under the literal translation, it would be rather difficult to understand the accurately expression of 
originals. At this time, the author can adopt the corresponding translation. Express the meaning of source language by using the certain fixed structure of target language. It often uses the verse, saying or proverb (Su, 2013).

谁跑到最后, 谁笑得最好. (某轮胎广告)

There is a proverb in English “He who laughs last laughs best”, and its translation is “谁笑到最后,谁笑得最好.” This advertisement is written by imitating the proverb, and it changes the first "laughs" of the original into "lasts". With the use of the rhetorical device of personification, it vividly highlights the characteristics of durability of tires.

百闻不如一尝. (某出口食品广告)

Tasting is believing.

There is a proverb in Chinese:百闻不如一见. It happens that there is also a corresponding proverb in English: Seeing is believing. This advertisement changes the “见” in the original Chinese proverb into “尝”, and alters the "seeing" in the original English proverb to the "tasting". When people hear this advertisement, people can't help to have a taste of the food $(\mathrm{Gu}, 2004)$.

Where there's light there is power. (Citizen Eco)

只要有光就有能量. (西铁城光动能表)

It is universally acknowledged that "where there is a will, there is a way." is a very popular proverb in English. This advertisement has replaced the "a will" and "a way" with "light" and "power" in original proverb, which emphasizes that "Citizen" watch can absorb any visible light, and then is transformed into kinetic energy driven watch operation. Using the original table circle of light absorption technology, the energy produced not only promotes the hand of watch, but also shakes the hearts of consumers. People who have ambitions will be successful. Through this proverb, the extraordinary quality of Citizen can be represented incisively and vividly.

Sense and Simplicity. (Philips)

精于心，筒于形. (飞利浦)

The advertising simulates one of famous works written by British novelist Jane Austen-Sense and Sensibility. It uses the rhetorical device of alliteration, which emphasizes that Philips's products have rich connotation and are easy to use. The author believes that people couldn't help but look for a few more time when they see things they are familiar with. Sense and Sensibility is known by people all over the world, which has a great influence. Therefore, using the name of this book can draw attention of people who know or like this book for the first time. It can arouse people's interest and achieve the effect of publicity.

It can be seen that the use of proverbs, idioms, sayings in the advertising translation can cause very different effect.

\section{Creative Translation}

Literary master Guo Moruo regarded translation as a kind of creative work in his 《谈文学翻译工作》. He said, "Translation is a kind of creative work, and good translation is equal to the creation, or even more than the creation. Translation is not a mediocre job, and it is more difficult than writing occasionally" (Guo, 1963, p.56). Creative translation requires that translator should have abundant knowledge, bold imagination and expanding thinking. Creative translation is the highest principle of advertising translation, because the soul of advertisement translation is the creativity.

Intel Inside. (Intel Pentium)

给电脑一颗奔腾的 “芯”.

The advertisement can be literally translated as“内藏英特尔”, and it can also paraphrase as“内含英特尔奔腾 CPU”. But the author has to admit that“给电脑一颗奔腾的“芯”” is the best one. Because it uses the rhetorical device of pun, the advertisement not only represents the powerful microprocessor and energetic driving force of Pentium, but also highlights the brand value, leading people to think that the Intel Pentium is the CPU, and CPU is the Intel Pentium.

Connecting People. (NOKIA)

科技以人为本. (诺基亚)

This is the advertising of NOKIA mobile phone. Its literal meaning is “联系人们”, showing that the mobile phone can bring convenience in people and call others wherever and whenever people like. The advertising emphasizes the factors of people and connects the function and idea of NOKIA which realizes the value of translation.

It happens at the Hilton. (Hilton)

希尔顿酒店有求必应.

Hilton Hotel, a well-known chain hotel, its business spreads all over the world. The translation adds to the meaning of Hotel Hilton clearly, and increases a Chinese four-character idiom “有求必应”, reflecting a good cultural atmosphere of the hotel.

Whether in English or Chinese advertising, its purpose is to promote the sales of products. In this sense, the quality of the translation of the advertisement plays an important role in the product sales. Therefore, the author should flexibility use various translation methods, and continue to broaden the knowledge for improving the quality 
of translation so that the advertisements can be accepted by consumers.

\section{CONCLUSION}

Advertising is a unique language, and it has distinct characteristics. Whether in terms of vocabulary, structure or rhetoric, it is different from other styles. Certain sentences, according to grammar, are fragmentary, but appearing in the advertisement can obtain very good effect. The use of rhetoric in advertising is also quite particular, resulting in a novel, unique, vivid, and eye-catching effect.

Every country has its own rich and splendid history, and rich culture and history of countries can also create the utterly different languages. The biggest gap of Chinese-English translation is the differences of cultural background in the aspects of cultural backgrounds, modes of thinking, aesthetic views, ethnic customs and habits which must be paid attention in the process of Chinese-English translation, otherwise there will be jokes (He, 2007).

Based on what is said above, this paper analyzes the application of the methods of literal translation, free translation, amplification, corresponding translation and creative translation in the translation of advertisements from the point of view of the characteristics and cultural factors. And these examples show that these methods can be used for advertising translation. The author should focus on the understanding of the original text and flexibility in the use of translation methods rather than too much stick to the original meaning and syntax. Only in this way, the author can ultimately achieve aims of advertising: on the one hand, it promotes consumers to take action to buy products; on the other hand, through the appreciation of the translation methods used by examples, it shows experiencing subtleties of language in advertisement translation.

Cross-cultural translation is very difficult, and it has a higher requirement for translators. Translators should possess excellent comprehensive competence of translation, including solid language skills, rich cultural knowledge and translation experience. However, along with the development of the trend of economic globalization, cross-cultural translation in advertising appears to be more and more important. The successful advertising translation is the key element for products to open up the market. It can not only bring economic benefits for enterprises, but also improve their reputation.

\section{REFERENCES}

[1] Eugene A Nida. (1993). Language, Culture and Translation. Shanghai: Shanghai Foreign Language Education Press.

[2] Gu Yunfeng. (2004). Language and Culture Differences and Their Impact on Advertisement Translation. Journal of Ningbo University, 2, 23-26.

[3] Guo Moruo. (1963).The literary translation. In Guo Moruo, The anthology of Guo Moruo. Beijing: People's Literature Publishing House, 178.

[4] He Xuefei. (2007). Research on cross-cultural advertising communication in the context of globalization. Beijing: China Social Sciences Publishing House.

[5] Li Kexing. (2010).Theory and practice in advertising translation. Beijing: Peking University Press.

[6] Newmark, P. (2001). A Textbook of Translation. Shanghai: Shanghai Foreign Language Education Press.

[7] Su Weiyun. (2013). Research on the purpose and strategy of advertising translation. Overseas English, 12, 166-168.

[8] Vestergaard, T. (1992). The Language of Advertising. Oxford: Blackwell Publishers.

[9] Wang Min. (2010). Language features and translation skills of English advertising. Journal of Tongling Vocational and Technical College, 1, 47-49.

[10] Wu Wenjie. (2012). The use of rhetorical devices in advertising. Language Planning, 12, 71-72.

[11] Zou Li. (2005). Translation Course of Business English. Beijing: China WaterPower Press.

Xin Zheng was born in Taiyuan, Shanxi in 1993. She received her bachelor's degree in English from LvLiang University, Shanxi in 2016.

She is currently a postgraduate studying for her master's degree and majoring in Foreign Linguistics and Applied Linguistics in Shanxi Normal University. Her research interests included sociolinguistics, second language acquisition and cognitive linguistics. 